\title{
Frações húmicas da matéria orgânica do solo cultivado com soja sobre palhada de braquiária e sorgo
}

\author{
Celeste Queiroz Rossi $\left({ }^{1 *}\right)$; Marcos Gervasio Pereira ( $\left.{ }^{2}\right)$; Simone Guimarães Giacomo $\left({ }^{2}\right)$; \\ Marconi Betta ( $\left.{ }^{3}\right)$; José Carlos Polidoro ( $\left.{ }^{4}\right)$ \\ (') Universidade Federal Rural do Rio de Janeiro (UFRRJ), Curso de Pós-Graduação em Agronomia - Ciência do Solo, BR 465, km 7. \\ 23890-000 Seropédica (RJ). \\ (2) UFRRJ, Departamento de Solos, 23890-000 Seropédica (RJ). \\ (3) Universidade do Rio Verde (FESURV), Caixa Postal 104, 75901-970 Rio Verde (GO). \\ (4) Embrapa Solos, 22460-000 Rio de Janeiro (RJ). \\ (*) Autora correspondente: celestegrossi@yahoo.com.br
}

Recebido: 27/jun./2010; Aceito: 6/dez./2010

\section{Resumo}

A matéria orgânica do solo (MOS) é o produto de resíduos da biota, principalmente dos vegetais, parcialmente decompostos e sintetizados, em vários estádios de complexidade e diversidade estrutural. A dinâmica da matéria orgânica influencia os principais processos químicos, físicos e biológicos nos solos, e determina muitas vezes sua fertilidade. O objetivo deste estudo foi quantificar o conteúdo de ácido fúlvico, ácido húmico e humina, e avaliar o estoque destas frações em Latossolo Vermelho, cultivado com soja sobre palhada de braquiária e sorgo no cerrado goiano, município de Montividiu (GO). As amostras foram coletadas em três profundidades nos seguintes sistemas agrícolas: área com cultivo de braquiária na entressafra da soja (SB) e outra com o cultivo de sorgo na entressafra da soja (SS). Foram analisados os teores de carbono orgânico total (COT) e realizado o fracionamento químico da matéria orgânica do solo. A partir dos valores analisados, foram quantificados os estoques de carbono em cada uma das frações. Foram verificadas diferenças significativas para os teores de COT entre sistemas avaliados em todas as profundidades. Quanto às frações químicas da matéria orgânica, observou-se que houve um predomínio da fração humina (C-HU) em relação às frações ácido húmico (C-FAH) e ácido fúlvico (C-FAF) nas duas coletas avaliadas.

Palavras-chave: matéria orgânica, fracionamento químico, plantio direto.

\section{Humic fractions of organic matter in soil cultivated with soybean on straw of brachiaria and sorghum}

\footnotetext{
Abstract

The soil organic matter (SOM) is the waste product of the biota, mainly of vegetables, partially decomposed and synthesized in various stages of complexity and structural diversity. The dynamics of organic matter influences the main chemical, physical and biological processes of soils, and often determines soil fertility. The objective of this study was to quantify the fulvic acid, humic acid and humin content and evaluate the stock of these fractions in an Oxisol cultivated with soybean on straw of grass and sorghum in a savanna, Montividiu county (GO). Soil samples were taken at three depths in an area with grass growing between soybean crops (SB) and the other with the cultivation of sorghum between soybean crops (SS). The chemical composition of total organic carbon (TOC) and chemical fractionation of soil organic matter were evaluated. From these values, the carbon stocks in each fraction were quantified. There were significant differences for the TOC levels between all systems evaluated and in all soil depths. Regarding the chemical fractions of organic matter, there was a predominance of the humin fraction ( $\mathrm{C}-\mathrm{HU})$ as compared to the the humic (C-FAH) and fulvic (C-FAF) acid fractions in the two samples evaluated.
}

Key words: organic matter; chemical fractionation; no-tillage. 


\section{INTRODUÇÃO}

O conteúdo de matéria orgânica do solo (MOS) é considerado um dos principais indicadores de sustentabilidade e qualidade ambiental em agroecossistemas. Sistemas conservacionistas de manejo promovem o aumento do conteúdo de MOS (SÁ et al., 2001), contribuindo para que o solo desempenhe suas funções básicas (promover a produção de alimentos e consequentemente, garantir a qualidade ambiental, a saúde animal e humana). A compreensão da dinâmica da MOS em sistemas de produção permite subsidiar o estabelecimento de estratégias de manejo que garantam o incremento do conteúdo de MOS e a qualidade ambiental e do solo ao longo do tempo. Embora contribua somente com uma pequena parcela da massa total dos solos minerais, a matéria orgânica do solo (MOS) representa a componente fundamental para a manutenção da qualidade do solo, sendo essencial nos diversos processos químicos, físicos e biológicos de ecossistemas terrestres (Piccolo, 1996; Christensen, 2000; CARTER, 2001).

A matéria orgânica do solo (MOS) é o produto de resíduos da biota, principalmente dos vegetais, parcialmente decompostos e sintetizados, em vários estádios de complexidade e diversidade estrutural (Silva e RescK, 1997; BATJEs, 1999). A dinâmica da matéria orgânica influencia os principais processos químicos, físicos e biológicos nos solos, e determina muitas vezes seu comportamento químico e fertilidade (Coleman et al., 1989; Hermle at al., 2008).

As substâncias húmicas $(\mathrm{SH})$ são misturas heterogêneas de polieletrólitos originadas pela degradação biológica de resíduos animais e vegetais e da atividade de microrganismos (STEvenson, 1994; Rocha et al., 2000; Rosa et al., 2001). Possuem alto teor de grupos funcionais contendo oxigênio na forma de carboxilas, hidroxilas fenólicas e carbonilas (JordÃo et al., 1993; SARGENTINI JÚNIOR et al., 2001).

Os ácidos húmicos são responsáveis pela maior capacidade de troca catiônica (CTC) de origem orgânica nas camadas superficiais do solo, onde estáo concentrados os resíduos culturais (Benites et al., 2003). Em estudos de alteração da MOS no Pantanal Sul-Matogrossense, FerNANDES et al. (1999) constataram a predominância de ácidos fúlvicos no cerrado intacto, representando 82,5\% de COT. Neste estudo, foi possível observar nas três profundidades amostradas, pouca redução das fraçôes húmicas entre as coletas e sistemas avaliados.

Metodologicamente as SH são fracionadas em função de sua solubilidade a diferentes valores de $\mathrm{pH}$ em: ácidos húmicos (AH), ácidos fúlvicos (AF) e humina (HUM). O presente trabalho teve como objetivo quantificar o carbono nas fraçôes ácido fúlvico, ácido húmico e humina, em um Latossolo Vermelho, cultivado com soja sobre palhada de braquiária e sorgo no cerrado goiano.

\section{MATERIAL E MÉTODOS}

O estudo foi realizado no município de Montividiu (GO). A área está inserida dentro do bioma do Cerrado e situa-se entre a latitude $17^{\circ} 27^{\prime} \mathrm{S}$ e longitude $51^{\circ} 04^{\prime} \mathrm{W}$. A altitude média verificada na área é de $930 \mathrm{~m}$. O clima da região é do tipo Aw (Köppen) - Tropical, com chuvas concentradas no verão e um período seco bem definido durante o inverno (Figura 1).

Nas áreas de estudo a soja é cultivada comercialmente, e em uma delas, no período da entressafra da soja, a braquiária é utilizada como planta de cobertura permanecendo na área durante todo o período de seca na região compreendido entre maio e novembro. Na outra área de estudo é realizado o cultivo de sorgo ou milho em sucessão à soja.

Para o estudo foram selecionadas duas áreas experimentais, a saber: área 1 (SB): soja (Glycine max L.)/ braquiária (Brachiaria ruziziensis)/ soja (Glycine max L.); e área 2 (SS) soja (Glycine max L.)/ sorgo (Sorghum bicolor L. Moench) variedade DKB 599/ soja (Glycine max L.). Como área de referência para o trabalho, foi utilizada área com floresta nativa de cerrado. O solo foi classificado como Latossolo Vermelho (Embrapa, 2006).

$\mathrm{Na}$ área de cada cobertura vegetal, foram delimitadas parcelas de $50 \times 50 \mathrm{~m}$, perfazendo uma área amostral de $2500 \mathrm{~m}^{2}$. Em cada área foram abertas oito (8) trincheiras com dimensões de 1 x $1 \mathrm{~m}$ e 0,6 m de profundidade (Figura 2). Em cada trincheira coletaram-se amostras em três (3) das quatro (4) paredes, sendo as amostras coletadas nas seguintes profundidades: 0-5; 5-10 e 10-20 cm. Foram coletadas amostras indeformadas, com o auxílio de um anel de Kopeck, para a análise da densidade do solo (Ds). Nas mesmas profundidades também foram coletas amostras deformadas para a caracterização química do solo.

A primeira amostragem foi realizada no início de março de 2007, após a colheita da soja, da safra de 2006/2007; a segunda coleta foi realizada no fim de outubro de 2007, coincidindo com o final do período seco da regiáo, quando a braquiária é manejada com herbicidas dissecantes (Glifosato e 2,4-D), para a implantação da lavoura de soja da safra de 2007/2008. Para a avaliação da produção da biomassa, após a colheita da soja, foi realizada uma amostragem em oito pontos na área experimental, com o auxílio de um quadrado metálico de $1 \mathrm{~m}^{2}$ de área, lançado aleatoriamente. Foi coletado todo o material contido na área delimitada por este quadrado. $\mathrm{O}$ material foi seco em estufa de circulação forçada a $65{ }^{\circ} \mathrm{C}$, por 72 horas, posteriormente pesado, sendo calculada a quantidade de material depositado. As áreas de estudo foram adubadas com $81,5 \mathrm{~kg} \mathrm{ha}^{-1}$ de $\mathrm{KCl} \mathrm{e}$ $332 \mathrm{~kg} \mathrm{ha}^{-1}$ do formulado 02-23-08.

Após a coleta, as amostras para a determinação da DS foram secas em estufa, durante 24 horas, a uma temperatura de $105-110{ }^{\circ} \mathrm{C}$; posteriormente, a DS foi determinada segundo Embrapa (1997). As amostras deformadas foram secas ao ar, destorroadas e passadas por peneira de 


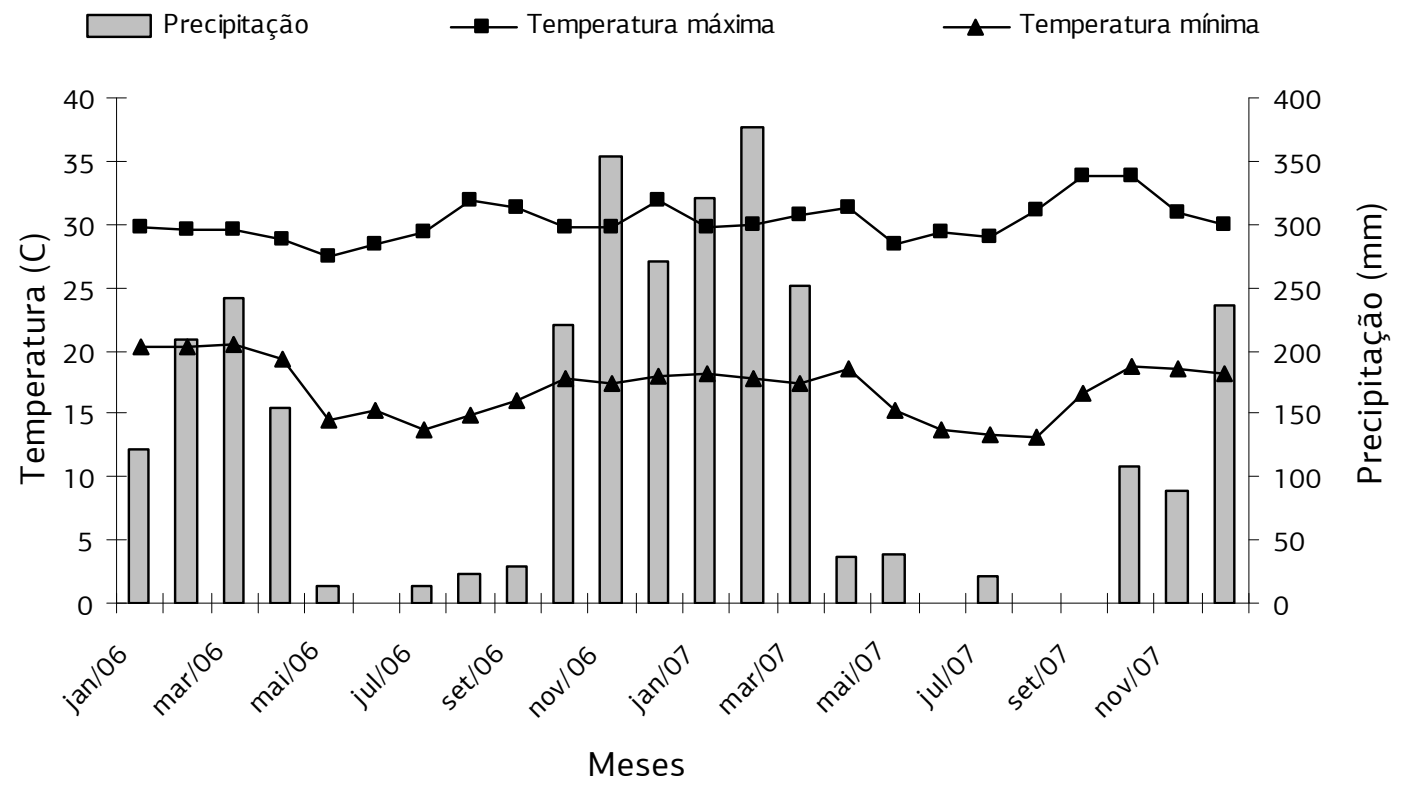

Figura 1. Dados climáticos mensais de temperatura e precipitação pluviométrica para os anos de 2006 e 2007. Rio Verde (GO).

2,00 mm de malha, obtendo-se assim a terra fina seca ao ar (TFSA). Para caracterização química das áreas foram realizadas as análises de $\mathrm{pH}, \mathrm{Ca}^{2+}, \mathrm{Mg}^{2+}, \mathrm{Na}^{+}, \mathrm{K}^{+}, \mathrm{P}, \mathrm{Al}^{3+}$, $\mathrm{H}+\mathrm{Al}$ de acordo com Embrapa (1997) (Tabela 1).

O carbono orgânico total (COT) foi determinado segundo Embrapa (1997). O estoque de carbono foi calculado pelo método da camada equivalente, e a correção dos estoques de carbono do solo realizada levando-se em conta as diferenças nas massas de solo de cada camada, segundo Sisti et al. (2004).

Para o fracionamento químico da MOS, foi utilizada a técnica de solubilidade diferencial (SwIFT, 1996), com adaptação de Benites et al. (2003), obtendo-se o carbono orgânico na fração ácidos fúlvicos (C-FAF), fração ácidos húmicos (C-FAH) e humina (C-HU).

Para tal, pesou-se uma massa de solo que possui $30 \mathrm{mg}$ de carbono orgânico submetendo-se ao contato com $20 \mathrm{~mL}$ de $\mathrm{NaOH} 0,1 \mathrm{~mol} \mathrm{~L}^{-1}$ por um tempo de 24 horas (EA). A separação entre o extrato alcalino $(\mathrm{EA}=\mathrm{FAF}+\mathrm{FAH})$ e $\mathrm{o}$ resíduo foi feita por centrifugação a $5000 \mathrm{~g}$ por 30 minutos. Seguiram-se mais uma lavagem com a mesma soluçáo, juntando-se o extrato com o anteriormente obtido, resultando em volume final de aproximadamente $40 \mathrm{~mL}$. O resíduo foi reservado para determinação da humina $(\mathrm{C}-\mathrm{HU}) . \mathrm{O} \mathrm{pH}$ do extrato alcalino (EA) foi ajustado a 1,0 com $\mathrm{H}_{2} \mathrm{SO}_{4} 20 \%$, seguido de decantação por 18 horas. O precipitado (C-FAH) foi separado da fração solúvel (C-FAF) por filtragem e ambos os volumes aferidos a $50 \mathrm{~mL}$ com água destilada.

A determinação quantitativa do carbono orgânico nas C-FAF e C-FAH foi feita usando-se alíquotas de $5,0 \mathrm{~mL}$ de extrato, $1,0 \mathrm{ml}$ de dicromato de potássio $0,042 \mathrm{moL} \mathrm{L}^{-1}$ e 5,0 $\mathrm{ml}$ de $\mathrm{H}_{2} \mathrm{SO}_{4}$ concentrado, em bloco digestor a 150 ${ }^{\circ} \mathrm{C}$ (30 minutos) e titulação com sulfato ferroso amoniacal

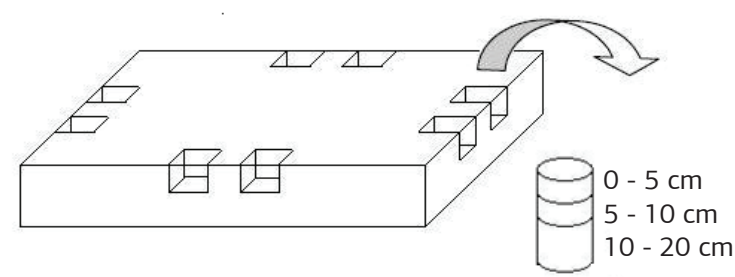

Figura 2. Esquema da área experimental com as minitrincheiras usadas para a coleta de solos.

0,0125 $\mathrm{mol} \mathrm{L}^{-1}$. No resíduo, foi determinado o carbono orgânico da fraçẫo humina (C-HU), após secagem do material em estufa a $65^{\circ} \mathrm{C}$ (secagem completa) e adicionando $5,0 \mathrm{~mL}$ de dicromato de potássio $0,1667 \mathrm{~mol} \mathrm{~L}^{-1} \mathrm{e} 10,0 \mathrm{~mL}$ de $\mathrm{H}_{2} \mathrm{SO}_{4}$ concentrado, em bloco digestor a $150^{\circ} \mathrm{C}(30 \mathrm{mi}-$ nutos) e titulação com sulfato ferroso amoniacal $0,25 \mathrm{~mol} \mathrm{~L}^{-1}$ (Yeomans e Bremner, 1988). A amostragem do solo realizada foi representativa da área, sendo dois sistemas de cultivos, três profundidades. Os resultados dos teores de carbono e das fraçôes húmicas obtidos para os diferentes tratamentos estudados foram submetidos ao teste de normalidade (Teste de Lilliefors) e homogeneidade das variâncias pelo teste de Cochran e Barttlet. Posteriormente, os resultados foram submetidos à análise de variância com a aplicação do teste Tukey a 5\% com o auxílio do programa estatístico SAEG versão 9.0 (Sistema de Análises Estatísticas e Genéticas - UFV).

\section{RESULTADOS E DISCUSSÃO}

A produção de biomassa seca na área onde se utiliza a braquiária como planta de cobertura foi de $6,0 \mathrm{Mg} \mathrm{ha}^{-1}$, 
já para a área onde se utiliza o sorgo foi de 3,2 $\mathrm{Mg} \mathrm{ha}^{-1}$. Estudando a dinâmica do $\mathrm{K}$ de resíduos de cobertura vegetal no Cerrado (Torres e Pereira, 2008) verificaram tendência contrária, ou seja, valores de biomassa seca de braquiária $\left(6,0 \mathrm{Mg} \mathrm{ha}^{-1}\right)$ inferiores aos observados na área de sorgo $\left(7,1 \mathrm{Mg} \mathrm{ha}^{-1}\right)$. Avaliando-se as taxas de decomposiçáo de resíduos de espécies de cobertura em Latossolo Vermelho em sistema de PD no município de Santo Antônio de Goiás (GO), Kliemann et al. (2006), verificaram a mesma tendência observada nesse estudo, ou seja, produção de biomassa seca de braquiária superior a $12,42 \mathrm{Mg} \mathrm{ha}^{-1}$ e de sorgo de 6,75 $\mathrm{Mg} \mathrm{ha}^{-1}$, a magnitude destes valores foi praticamente o dobro da observada nesse estudo.
Quanto ao carbono orgânico total (COT), os maiores valores foram verificados no sistema $S B$ e SS na camada de $0-5 \mathrm{~cm}$, sendo observada reduçáo dos teores em profundidade (Tabela 2). Esse padráo pode ser explicado pela deposição de material proveniente do plantio direto praticado nas áreas de estudo em detrimento à área de referência. Para as demais profundidades não foram verificadas diferenças estatísticas entre o sistema $\mathrm{SB}$ e a área de referência, contudo os valores observados em SB foram superiores aos observados no sistema SS (Tabela 2). Na segunda coleta também foram observados valores decrescentes de COT em profundidade. Para a camada de 0-5 $\mathrm{cm}$ tanto o sistema SB quanto área de referência tiveram valores estatisticamente superiores aos constatados no

Tabela 1. Propriedades químicas do solo nos sistemas avaliados

\begin{tabular}{|c|c|c|c|c|c|c|c|c|c|c|}
\hline Sistemas ${ }^{(1)}$ & SB & SS & SB & SS & SB & SS & SB & SS & SB & SS \\
\hline Prof. & \multicolumn{2}{|c|}{ valor S } & \multicolumn{2}{|c|}{ Al } & \multicolumn{2}{|c|}{$\mathrm{H}+\mathrm{Al}$} & \multicolumn{2}{|c|}{$\mathrm{pH}$} & \multicolumn{2}{|c|}{$\mathbf{P}$} \\
\hline $\mathrm{cm}$ & \multicolumn{6}{|c|}{$\mathrm{cmol}_{\mathrm{c}} \mathrm{dm}^{-3}$} & \multicolumn{4}{|c|}{$\left(\mathrm{mg} \mathrm{kg}^{-1}\right)$} \\
\hline $0-5$ & 6,26 & 5,17 & 0 & 0 & 3,29 & 2,63 & 5,89 & 5,88 & 3,46 & 3,14 \\
\hline $5-10$ & 2,67 & 3,05 & 0 & 0 & 4,51 & 3,03 & 5,29 & 5,48 & 5,57 & 3,26 \\
\hline $10-20$ & 2,11 & 2,43 & 0 & 0 & 4,29 & 2,84 & 5,17 & 5,44 & 1,89 & 1,49 \\
\hline
\end{tabular}

(') SB: cultivo de soja no período chuvoso e braquiária no período seco; SS: cultivo de soja na safra e sorgo na safrinha. S: soma de bases.

Tabela 2. Carbono orgânico total (COT), estoque de carbono (EC), densidade do solo (Ds), carbono na fração ácido fúlvico (C-FAF), carbono na fraçáo ácido húmico $(\mathrm{C}-\mathrm{FAH})$ e carbono na fração humina $(\mathrm{C}-\mathrm{HU})$ entre as coletas nos sistemas de manejo avaliados

\begin{tabular}{|c|c|c|c|c|c|c|}
\hline \multirow{2}{*}{ Sistemas ${ }^{(1)}$} & \multicolumn{6}{|c|}{ Profundidade $(\mathrm{cm})$} \\
\hline & $0-5$ & $5-10$ & $10-20$ & $0-5$ & $5-10$ & $10-20$ \\
\hline & \multicolumn{3}{|c|}{ 1. ${ }^{a}$ Coleta (Março 2007) } & \multicolumn{3}{|c|}{ 2. a coleta (Outubro 2007) } \\
\hline & \multicolumn{6}{|c|}{ COT $\left(\mathrm{g} \mathrm{kg}^{-1}\right)$} \\
\hline SB & $24,9 \mathrm{~A}$ & $21,30 \mathrm{~A}$ & $19,7 \mathrm{~A}$ & $21,6 \mathrm{~A}$ & $19,0 \mathrm{~B}$ & $17,8 \mathrm{~B}$ \\
\hline SS & $23,9 \mathrm{~B}$ & $19,0 \mathrm{~B}$ & $16,7 \mathrm{~B}$ & $19,5 \mathrm{~B}$ & $17,0 \mathrm{C}$ & $16,3 \mathrm{~B}$ \\
\hline \multirow[t]{2}{*}{ A. REF } & $21,8 \mathrm{C}$ & $22,6 \mathrm{~A}$ & $19,7 \mathrm{~A}$ & $21,8 \mathrm{~A}$ & $22,6 \mathrm{~A}$ & $19,8 \mathrm{~A}$ \\
\hline & \multicolumn{6}{|c|}{ EC $\left(\mathrm{Mg} \mathrm{ha}^{-1}\right)$} \\
\hline SB & $13,3 \mathrm{~A}$ & $11,3 \mathrm{AB}$ & $22,9 \mathrm{~A}$ & $12,3 \mathrm{~A}$ & $11,4 \mathrm{~B}$ & $21,6 \mathrm{~B}$ \\
\hline SS & $11,6 \mathrm{AB}$ & $10,0 \mathrm{~B}$ & $20,0 \mathrm{~B}$ & $10,7 \mathrm{~B}$ & $10,4 \mathrm{~B}$ & $20,0 \mathrm{~B}$ \\
\hline \multirow[t]{2}{*}{ A. REF } & $11,4 \mathrm{~B}$ & $12,5 \mathrm{~A}$ & $23,4 \mathrm{~A}$ & $12,3 \mathrm{~A}$ & $13,4 \mathrm{~A}$ & $24,4 \mathrm{~A}$ \\
\hline & \multicolumn{6}{|c|}{ Ds $\left(\mathrm{kg} \mathrm{dm}^{-3}\right)$} \\
\hline SB & $1,01 \mathrm{~B}$ & $1,15 \mathrm{~B}$ & $1,17 \mathrm{~B}$ & $1,09 \mathrm{~B}$ & $1,19 \mathrm{~B}$ & $1,21 \mathrm{C}$ \\
\hline SS & $1,21 \mathrm{~A}$ & $1,31 \mathrm{~A}$ & $1,31 \mathrm{~A}$ & $1,22 \mathrm{~A}$ & $1,32 \mathrm{~A}$ & $1,33 \mathrm{~B}$ \\
\hline \multirow[t]{2}{*}{ A. REF } & $1,24 \mathrm{~A}$ & $1,34 \mathrm{~A}$ & $1,44 \mathrm{~A}$ & $1,23 \mathrm{~A}$ & $1,34 \mathrm{~A}$ & $1,44 \mathrm{~A}$ \\
\hline & \multicolumn{6}{|c|}{ C-FAF $\left(\mathrm{g} \mathrm{kg}^{-1}\right)$} \\
\hline SB & $3,0 \mathrm{~A}$ & $3,0 \mathrm{~A}$ & $3,6 \mathrm{~A}$ & $3,6 \mathrm{~A}$ & $3,4 \mathrm{~A}$ & $3,4 \mathrm{~A}$ \\
\hline SS & $2,7 \mathrm{~A}$ & $2,6 \mathrm{~A}$ & $2,9 \mathrm{~B}$ & $2,7 \mathrm{~B}$ & $2,8 \mathrm{~B}$ & $2,6 \mathrm{~B}$ \\
\hline \multirow[t]{2}{*}{ A. REF } & $2,6 \mathrm{~A}$ & $2,2 \mathrm{~B}$ & $1,6 \mathrm{C}$ & 2,6 B & $2,2 \mathrm{C}$ & $1,6 \mathrm{C}$ \\
\hline & \multicolumn{6}{|c|}{ C-FAH $\left(\mathbf{g ~ k g}^{-1}\right)$} \\
\hline SB & $3,6 \mathrm{~A}$ & $3,3 \mathrm{~A}$ & $2,8 \mathrm{~A}$ & $3,4 \mathrm{~A}$ & $2,6 \mathrm{~B}$ & $2,8 \mathrm{~A}$ \\
\hline SS & $2,9 \mathrm{~B}$ & $2,7 \mathrm{AB}$ & $1,6 \mathrm{~B}$ & $3,2 \mathrm{~B}$ & $3,2 \mathrm{~A}$ & $3,0 \mathrm{~A}$ \\
\hline \multirow[t]{2}{*}{ A. REF } & $3,0 \mathrm{~B}$ & $2,1 \mathrm{~B}$ & $1,2 \mathrm{C}$ & $3 \mathrm{~B}$ & $2,1 \mathrm{~B}$ & $1,2 \mathrm{~B}$ \\
\hline & \multicolumn{6}{|c|}{ C-HU $\left(\right.$ g kg-1) $^{-1}$} \\
\hline SB & $11,9 \mathrm{~A}$ & $9,5 \mathrm{~A}$ & $9,2 \mathrm{~A}$ & $9,8 \mathrm{~A}$ & $8,1 \mathrm{~A}$ & $8,2 \mathrm{~A}$ \\
\hline SS & $9,4 \mathrm{~B}$ & $7,8 \mathrm{~B}$ & $6,9 \mathrm{~B}$ & $6,4 \mathrm{~B}$ & $6,4 \mathrm{~B}$ & $3,9 \mathrm{~B}$ \\
\hline A. REF & $5,3 \mathrm{C}$ & $3,5 \mathrm{C}$ & $1,9 \mathrm{C}$ & $5,3 \mathrm{~B}$ & $3,5 \mathrm{C}$ & $1,9 \mathrm{C}$ \\
\hline
\end{tabular}

(1) SB: cultivo de soja no período chuvoso e braquiária no período seco; SS: cultivo de soja na safra e sorgo na safrinha; A.REF: área de referência. Médias seguidas da mesma letra nấo diferem pelo teste de Tukey a p>0,05. 
sistema SS; já para as profundidades de 5-10 e 10-20 cm houve um aumento significativo dos teores de COT da área de referência em relação aos sistemas SB e SS.

Estudando o efeito do preparo de solo nos estoques de carbono do solo sob rotação de culturas de longo prazo na região do cerrado brasileiro, JANTALIA et al. (2007) verificaram que todos os tipos de preparo do solo tiveram efeito negativo nos estoques de carbono do solo até $30 \mathrm{~cm}$ de profundidade em relação à área de Cerrado nativo.

Os menores valores médios de densidade do solo (Ds) foram verificados nas camadas mais superficiais nos sistemas avaliados, decorrente da constante adição de matéria orgânica e do menor revolvimento do solo em SPD. Nos sistemas avaliados os valores médios de Ds variaram de 1,01 a 1,44 $\mathrm{Mg} \mathrm{m}^{-3}$ (Tabela 2); os maiores valores sempre foram observados na área de referência seguida do sistema SS e SB, independentes da coleta.

Em estudos de COT em Latossolos sob diferentes sistemas de manejo, Freitas et al. (2000) constataram valores de Ds variando de 1,10 a $1,32 \mathrm{Mg} \mathrm{dm}^{-3}$, e também verificaram maior Ds na camada de $10-20 \mathrm{~cm}$ quando comparadas às outras profundidades.

Os valores de EC na $1 .^{\circ}$ coleta náo diferiram entre os sistemas avaliados até $10 \mathrm{~cm}$ de profundidade; para a camada de 10-20, o sistema SB e a área de referência foram superiores ao sistema SS (Tabela 2). Para a segunda coleta, o sistema SS proporcionou valores inferiores quando comparados ao sistema $\mathrm{SB}$ e a área de referência nas camadas de $0-5 \mathrm{~cm}$; nas demais profundidades, os valores foram estatisticamente superiores na área de referência.

Em estudos sobre estoques totais de COT e seus compartimentos em Argissolo sob floresta e sob milho cultivado com adubação mineral e orgânica, Leite et al. (2003) verificaram que todos os sistemas que utilizavam somente adubação mineral contribuíram para maiores reduçôes dos teores de COT na camada de 0-10 cm e um aumento na camada de 10-20 cm em relação à área de Floresta Atlântica. No entanto, os sistemas que utilizaram adubação orgânica foram mais eficientes em preservar os estoques de COT.

Com relaçáo ao fracionamento químico, verificou-se predomínio da fração humina (C-HU), em detrimento às fraçôes ácidos húmicos (C-FAH) e das fraçôes ácidos fúlvicos (C-FAF) (Tabela 2). Em diversos estudos em solos tropicais também se observou predomínio do carbono da fração humina em relação às outras frações (CONTEH e Blair, 1998; Assis et al. 2006). As huminas são substâncias altamente desenvolvidas e resistentes à degradação microbiana, fortemente combinada à fração mineral do solo, principalmente em solos oxídicos (STEVENSON, 1994; Sparks, 2001). Os elevados valores de C-HU podem estar relacionados ao tamanho das moléculas e ao maior grau de estabilidade desta fração. As frações C-FAF e C-FAH, por apresentarem menor estabilidade, podem ser polimerizadas ou mineralizadas, e diminuir assim, seu teor residual no solo (FonTANA et al., 2006).

Para C-HU foi verificada diferença estatística em todas as profundidades, sendo observados valores de 11,90 a 9,2 $\mathrm{g} \mathrm{kg}^{-1}$ para o sistema $\mathrm{SB}$ e 9,40 a $6,90 \mathrm{~g} \mathrm{~kg}^{-1}$ para o sistema SS na primeira coleta e valores de 9,80 a 8,10 $\mathrm{g} \mathrm{kg}^{-1}$ para o sistema $\mathrm{SB}$ e 6,40 a $3,90 \mathrm{~g} \mathrm{~kg}^{-1}$ para o sistema SS na segunda coleta. Maiores valores de carbono na fração C-HU, na maioria das vezes implicam maior expressão das propriedades da fração coloidal da matéria orgânica, tais como: retenção da umidade, melhor agregação do solo e maior retenção de cátions, características de grande importância quando se trata do cultivo de sistemas sustentáveis de produção (Souza e Melo, 2003).

Estudando uso da terra e propriedades físicas e químicas de Argissolo Amarelo distrófico na Amazônia ocidental também ArAújo et al. (2004) constataram maiores valores de carbono na fração C-HU em detrimento das fraçōes C-FAF e C-FAH, corroborando aos resultados deste estudo. Os autores verificaram ainda que as maiores variaçóes relativamente às três fraçôes ocorrem nos primeiros centímetros do solo.

Analisando os teores de carbono orgânico nas fraçōes granulométricas e a distribuição das substâncias húmicas em Latossolo Vermelho-Amarelo distrófico sob diferentes agrossistemas na Amazônia, Martins et al. (2009) encontraram os maiores valores de C-HU no sistema agrosilvopastoril com braquiária (Brachiaria brizantha), em detrimento ao sistema em que a braquiária foi utilizada como pastagem extensiva. Os autores atribuem esse padrão aos baixos níveis de lignina encontrados na gramínea a qual pode ser um dos precursores químicos para a formação da humina. Assim, solos sob pastagem possuem matéria orgânica menos recalcitrante e, portanto, são mais sensíveis às variações climáticas, químicas e microbiológicas que resultem em maior velocidade de degradação da matéria orgânica do solo (SANTOS e CAMARgo, 1999).

Em estudos sobre o carbono e nitrogênio em agregados de Latossolo submetido a diferentes sistemas de uso e manejo (PDs: plantio direto (milho/silagem); PDg: plantio direto (milho/grão); PDtf: plantio direto tifton; SC: plantio de soja em sistema convencional ; MN: mata nativa) no Estado de Minas Gerais, Assis et al. (2006) verificaram menor conteúdo da fração humina na área PDtf em todas as camadas e classes de agregados avaliados, os autores atribuem o menor acúmulo à alta relação $\mathrm{C} / \mathrm{N}$ do tifton é uma gramínea perene que possui, o que lhe confere maior tempo de decomposição quando comparadas aos outros sistemas.

Estudando estoques de carbono e quantificação de substâncias húmicas em Latossolo submetido à aplicação contínua de lodo de esgoto Dias et al. (2007) verificaram maior teor da fração humina em detrimento das fraçóes ácido fúlvico e ácido húmico; os autores atribuem essa maior presença de humina do solo à estabilidade da ligação 
que existe entre esse componente e a fase mineral do solo, assim como devido à maior resistência à decomposição dessa fração húmica (STEVEnson, 1982).

Em estudos de fracionamento químico e físico do carbono orgânico total em um solo de mata submetido a diferentes usos, BARRETo et al. (2008) verificaram que o maior percentual de $\mathrm{C}$ orgânico foi observado na fração humina em todos os sistemas estudados. No solo sob pastagem, o teor de $\mathrm{C}$ orgânico na fração humina supera o cultivado com cacau na profundidade de $0-10 \mathrm{~cm}$, mas, quando comparado com o sistema mata, não diferem estatisticamente. Provavelmente, as gramíneas, por serem plantas C4, contribuem para elevar e manter os aportes de $\mathrm{C}$ no solo e seu sistema radicular também aporte grande quantidade de $\mathrm{C}$, indicando maior estabilização do $\mathrm{C}$ pelo aumento na fração humina.

O estoque total de carbono orgânico e seus compartimentos, em um Argissolo sob floresta e milho cultivado com adubação mineral e orgânica em Viçosa (MG), foi avaliado por RosAles et al. (1999). Os autores verificaram maiores valores de C-HU em todos os sistemas de produção, atribuindo esse resultado ao tamanho das moléculas e ao longo tempo de implantação do experimento. Também foi constatada que a fração C-HU constitui cerca de 60\% do COT, resultados que corroboram com os encontrados nesse estudo.

$\mathrm{O}$ padrão verificado nesse estudo no tocante às substâncias húmicas, principalmente no sistema $\mathrm{SB}$, pode ser decorrente do denso sistema radicular das gramíneas, que em contato com as partículas minerais, promove aumento na qualidade e quantidade da matéria orgânica adicionada ao solo, favorecendo um incremento de fraçóes mais humificadas (Pinheiro et al., 2003).

Estudando áreas de savanas inundáveis na Colômbia sob solos arenosos, (ANDrEux e BECERRA, 1975) observaram predomínio da fração ácido fúlvico em relação aos ácidos húmicos, verificando que nas áreas com solos mais arenosos, a alta porosidade favoreceu a translocação dos precursores húmicos em profundidade. Além disso, a baixa disponibilidade de água nas camadas superficiais durante a estação seca é um fator limitante para a polimerização desses precursores, representado por valores altos na relação ácidos fúlvicos.

Avaliando as alteraçóes químicas de um Argissolo Vermelho-Amarelo de textura arenosa no horizonte superficial sob SPD, RHEINHEIMER et al. (1998), verificaram valores de C-FAF na camada de $0-5 \mathrm{~cm}\left(2,38 \mathrm{~g} \mathrm{~kg}^{-1}\right)$ e na camada de $20-40 \mathrm{~cm}$ valores 10 vezes mais baixos $(0,28 \mathrm{~g}$ $\left.\mathrm{kg}^{-1}\right)$. Esses autores ressaltam que em sistemas de plantio direto a não-incorporação dos resíduos culturais promove intenso processo biológico nas camadas superficiais do solo, de forma que haja grande e constante quantidade de carbono facilmente decomponível, influenciando diretamente na dinâmica do sistema, inclusive na complexação de alumínio e na disponibilidade de nutrientes. Com a atividade microbiana mais equilibrada, os processos de ressíntese das substâncias húmicas são favorecidos, aumentando seus teores, especialmente C-FAF e C-FAH.

Os estoques de C-HU, C-FAF e C-FAH seguiram o mesmo padrão que as frações húmicas. Os maiores valores de C-HU foram verificados na $1 .^{\text {a }}$ coleta nos dois sistemas avaliados em todas as profundidades (Figuras 3 e 4).

A área de referência seguiu o mesmo padrão de distribuição de carbono nas frações húmicas. Os maiores valores foram verificados na fração C-HU em todas as profundidades nas duas coletas, seguidos por C-FAF e
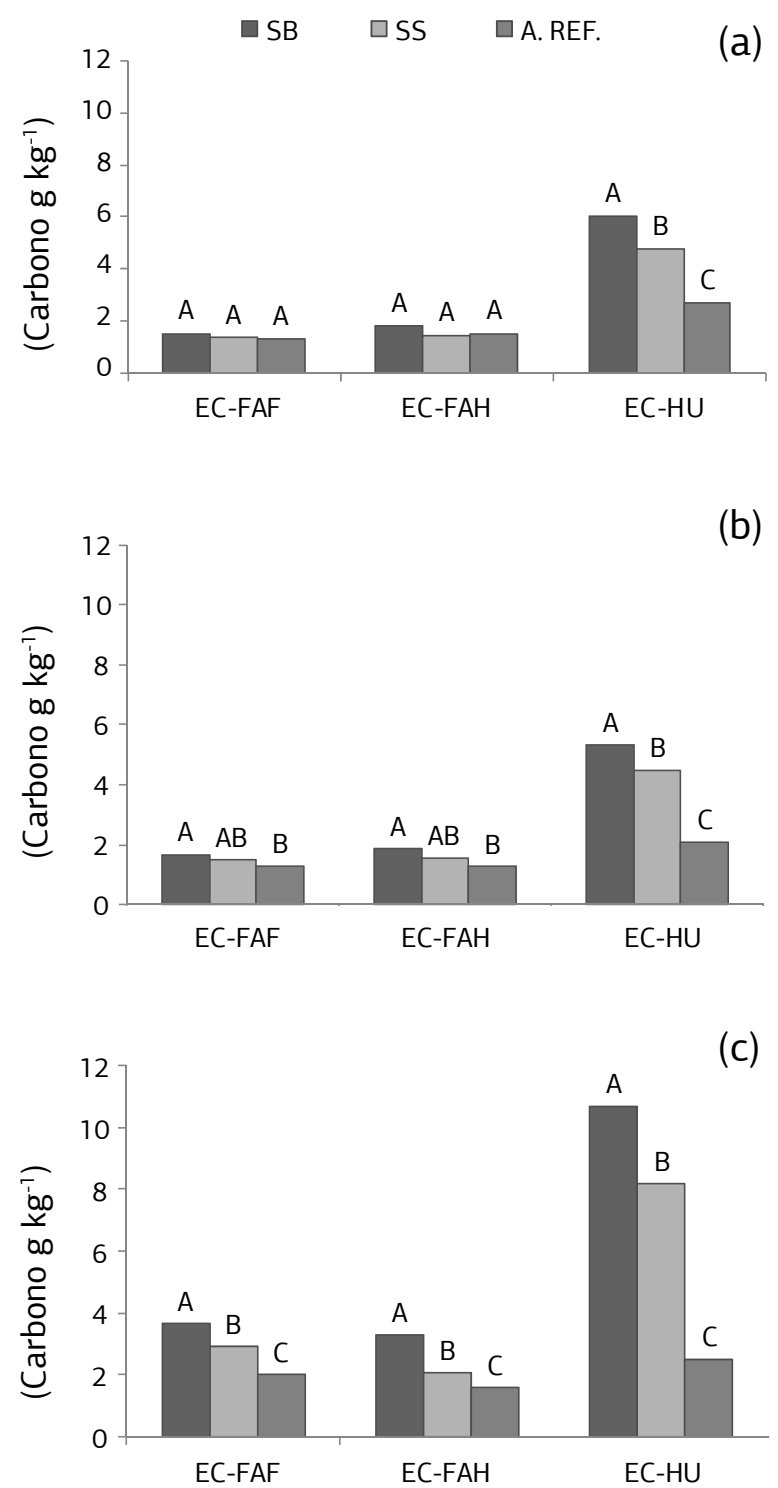

Figura 3. Estoque de carbono da fração ácido fúlvico (EC-FAF); na fração ácido húmico (EC-FAH); na fração humina (EC-HU) na primeira coleta (março de 2007) em Latossolo Vermelho submetido a dois tipos de manejo: Soja no período chuvoso e braquiária no período seco (SB); Soja na safra e sorgo na safrinha (SS) e área de referência (A. Ref). (a) $0-5 \mathrm{~cm}$ de profundidade; (b) $5-10 \mathrm{~cm}$ de profundidade; (b) 10-20 $\mathrm{cm}$ de profundidade. Médias seguidas da mesma letra não diferem pelo teste de Tukey $p>0,05$. 
C-FAH, porém os valores dessas fraçôes foram inferiores nas profundidades de 5-10 e 10-20 cm, quando comparados aos sistemas avaliados neste estudo (Tabela 2 e Figura 3). Fernandes et al. (1999) verificaram padráo diferente para a distribuição das substâncias húmicas ao estudar as alteraçôes da matéria orgânica em Podzol Hidromórfico (Espodossolo), onde a maior fraçáo encontrada no cerrado nativo foi a fração C-FAF. Nesse mesmo estudo, os autores observaram que o cerrado nativo sempre proporcionou maiores valores dessa fraçáo quando comparada aos sistemas avaliados.

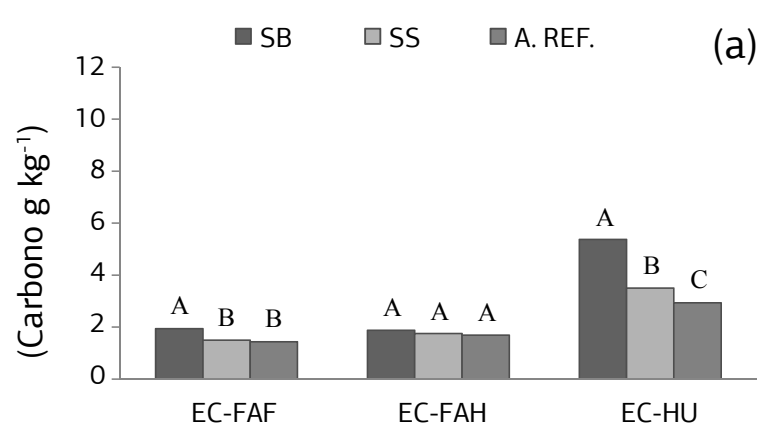

(b)
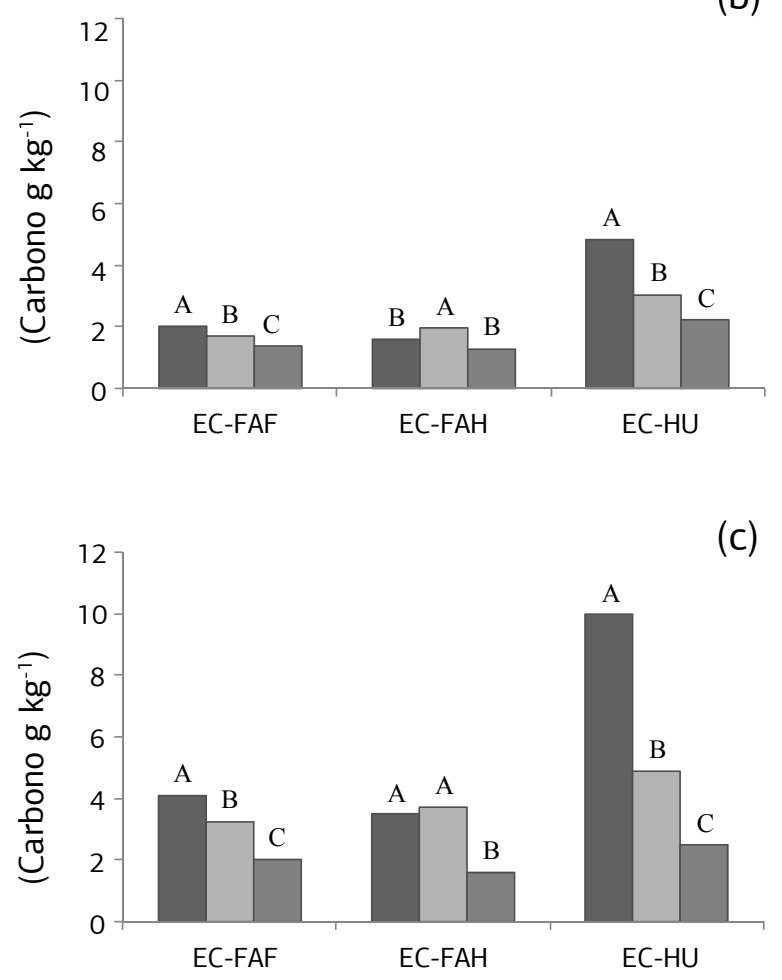

Figura 4. Estoque de carbono da fração ácido fúlvico (EC-FAF); na fração ácido húmico (EC-FAH); na fração humina (EC-HU) na segunda coleta (outubro de 2007) em Latossolo Vermelho submetido a dois tipos de manejo: Soja no período chuvoso e braquiária no período seco (SB); Soja na safra e sorgo na safrinha (SS) e área de referência (A. Ref). (a) 0-5 cm de profundidade; (b) 5-10 $\mathrm{cm}$ de profundidade; (c) 10-20 $\mathrm{cm}$ de profundidade. Médias seguidas da mesma letra não diferem pelo teste de Tukey $\mathrm{p}>0,05$.

\section{CONCLUSÃO}

O teor de C orgânico total difere entre os diferentes sistemas utilizados nas profundidades de 0-5, 5-10 e 10-20 $\mathrm{cm}$. A introdução de braquiária no cultivo da soja, em sistema de plantio direto, proporciona efeito positivo, favorecendo o acúmulo de carbono na fração humina (C-HU), nas épocas avaliadas.

O uso do solo sob vegetaçáo de cerrado para a produção agrícola, independentemente do sistema de cultivo, náo resulta em modificaçôes nos teores de carbono e de suas fraçōes químicas.

O fracionamento químico da MOS é uma ferramenta útil para identificar mudanças provenientes das práticas e sistemas agrícolas utilizados sob plantio direto.

\section{AGRADECIMENTOS}

Os autores agradecem ao Curso de Pós-Graduação em Agronomia - Ciência do solo. CPGA-CS, à Embrapa Solos e ao Conselho Nacional de Desenvolvimento Científico e Tecnológico (CNPq), pelo apoio e suporte financeiro.

\section{REFERÊNCIAS}

ANDREUX, F.; BECERRA, S.P. Fraccionamiento y caracterización del material húmico en algunos suelos de sabana de la Orinoquia Colombiana. Turrialba, v.25, p. 191-198, 1975.

ARAÚJO, A.E.; LANI, J.L.; AMARAL, E.A.; GUERRA, A. Uso da terra e propriedades físicas e químicas de Argissolo Amarelo Distrófico na Amazônia ocidental. Revista Brasileira de Ciência do Solo, v.28, p.307-315, 2004.

ASSIS, C.P.; JUCKSCH, I.; SÁ MENDONÇA, E.; NEVES, J.C.L. Carbono e nitrogênio em agregados de Latossolo submetido a diferentes sistemas de uso e manejo. Pesquisa Agropecuária Brasileira, v.41, p.1541-1550, 2006.

BARRETO, A.C.; FREIRE, M.B.G.S.; NACIF, P.G.S.; ARAÚJO, Q.R.; FREIRE, F.J.; INÁCIO, E.S.B. Fracionamento químico e físico do carbono orgânico total em um solo de mata submetido a diferentes usos. Revista Brasileira de Ciência do Solo, v. 32, p. 1471-1478, 2008.

BATJES, N.H. Management options for reducing $\mathrm{CO}_{2}-$ concentrations in the atmosphere by increasing carbon sequestration in the soil. Wageningen: Internacional Soil Reference and Information Centre, 1999. 114p. (Report 410-200-031. Dutch National Research Programme on Global Air Pollution and Climate Change \& Techinal. Paper 30)

BENITES, V.M.; MADARI, B.; MACHADO, P.L.O. A. Extração e fracionamento quantitativo de substâncias húmicas do solo: um procedimento simplificado de baixo custo. Rio de Janeiro: Embrapa Solos, 2003. 7p. (Comunicado Técnico, 16) 
CARTER, M.R. Organic matter and sustainability. In: REES, R.M.; BALL, B.C.; CAMPBELL, C.D.; WATSON, C.A. (Ed.). Sustainable management of soil organic matter. New York: CABI Publishing, 2001. p.9-22.

CHRISTENSEN, B.T. Organic matter in soil: structure, function and turnover. Tjele: DIAS. 2000. 95p. (DIAS Report. Plant Production, 30)

COLEMAN, D.C., OADES, J.M., UEHARA, G. Dynamics of soil organic matter in tropical ecossystems. Honolulu: NifTAL Project, University of Hawaii at Manoa, USA, 1989. p.173-200.

CONTEH, A.; BLAIR, G.J. The distribution and relative losses of soil organic carbon fractions in aggregate size fractions from cracking clay soils (vertisols) under cotton production. Australian Journal of Soil Research, v.36, p.257-271,1998.

DIAS, B.O.; SILVA, C.A ; SOARES, E.M.B., BETTIOL, W. Estoque de carbono e quantificação de substâncias húmicas em Latossolo submetido a aplicação contínua de lodo de esgoto. Revista Brasileira de Ciência do Solo, v.31, p.701-711, 2007.

EMPRESA BRASILEIRA DE PESQUISA AGROPECUÁRIA. Centro Nacional de Pesquisa de Solos. Manual de métodos de análise de solo. 2.ed. Rio de Janeiro, Embrapa Solos, 1997. 212p.

EMPRESA BRASILEIRA DE PESQUISA AGROPECUÁRIA. Centro Nacional de Pesquisa de Solos. Sistema brasileiro de classificação de solos. 2.ed. Rio de Janeiro: Embrapa Solos, 2006. 306p.

FERNANDES, A.F.; CERRI, C.C.; FERNANDES, A.H.B.M. Alteraçốes na matéria orgânica de um Podzol hidromórfico pelo uso com pastagens cultivadas no Pantanal Mato-Grossense. Pesquisa Agropecuária Brasileira, v. 34, p.1943-1951, 1999.

FONTANA, A.; PEREIRA, M.G.; LOSS, A.; CUNHA, T.J.F.; SALTON, J.C. Atributos de fertilidade e fraçóes húmicas de um Latossolo Vermelho no Cerrado. Pesquisa Agropecuária Brasileira, v.41, p.847-853, 2006.

FREITAS, P.L.; BLANCANEAUX, P.H.; GAVINELLI, E.; LARRÉ-LARROUY, M. C.; FELLER, C. Nível e natureza do estoque orgânico de Latossolos sob diferentes sistemas de uso e manejo. Pesquisa Agropecuária Brasileira, v.35, p.157-170, 2000.

HERMLE, S.; ANKEN, T.; LEIFELD, J.; WEISSKOPF. The effect of the tillage system on soil organic carbon content under moist, cold-temperate conditions. Soil and Tillage Research, v. 98, p.94105, 2008.

JANTALIA, C.P; RESCK, D.V.S.; ALVES, B.J.R..; ZOTARELLI, L.; URQUIAGA, S.; BODDEY, R.M. Tillage effect on C stocks of a clayey Oxisol under a soybean-based crop rotation in the Brazilian Cerrado region. Soil and Tillage Research, v.95, p.97-109, 2007.

JORDÃO, C.P.; COSTA, E.D.; BRUNE, W.; GOURLART, A.T. Adsorção de cátions metálicos em ácidos húmicos de Latossolo. Química Nova, v.16, p.517-520, 1993.

KLIEMANN, J.H.; BRAZ, A.J.P.B.; SILVEIRA, P.M. Taxas de decomposição de resíduos de espécies de cobertura em latossolo vermelho Distroférrico. Pesquisa Agropecuária Tropical, v.36, p. 21-28, 2006

LEITE, L.F.C.; MENDONÇA, E.S.; NEVES, J.C.L.; MACHADO, P.L.O.A.; GALVÃO, J.C.C. Estoques totais de carbono orgânico e seus compartimentos em Argissolo sob floresta e sob milho cultivado com adubação mineral e orgânica. Revista Brasileira de Ciência do Solo, v. 27, p. 821-832, 2003.

MARTINS, E.L.; CORINGA, J.E.S.; WEBER, O.L.S. Carbono orgânico nas fraçôes granulométricas e substâncias húmicas de um Latossolo Vermelho Amarelo distrófico - LVAd sob diferentes agrossistemas. Acta Amazonica, v. 39, p.655-660, 2009.

PICCOLO, A. Humus and soil conservation. In: PICCOLO, A. (Ed.). Humic substances in terrestrial ecosystems. Amsterdam: Elsevier, 1996. p.225- 264.

PINHEIRO, E.F.M.; PEREIRA, M.G.; ANJOS, L.H.C.; PALMIERI; SOUZA, R.C.; Matéria orgânica em Latossolo Vermelho submetido a diferentes sistemas de manejo e cobertura do solo. Revista Brasileira de Agrociência, v.9, p.53-56, 2003.

RHEINHEIMER, D.S.; KAMINSKI, J.; LUPATINI, G.C.; SANTOS, E.J.S. Modificaçóes em atributos químicos de solo arenoso sob sistema plantio direto. Revista Brasileira de Ciência do Solo, v.22, p.713-721, 1998.

ROCHA, J.C.; SARGENTINI JUNIOR, É.; ZARA, L.F.; ROSA, A.H.; SANTOS, A.; BURBA, P. Reduction of mercury(II) by tropical river humic substances (Rio Negro) - A possible process of the mercury cycle in Brazil. Talanta, v.53, p.551-559. 2000.

ROSA, A.H.; ROCHA, J.C.; SARGENTINI JUNIOR, É. A flow procedure for extraction and fractionation of the humic substances from soils. In: SWIFT, R.S.; SPARK, K.M., (Ed.). Understanding and managing organic matter in soils, sediments and waters. New York: International Humic Substances Society, 2001. p.41-46.

ROSALES, M.A.; OLIVEIRA, O.S.; MOURA, M.A.; LOURES, E.G. Influência das adubaçôes orgânica e mineral contínuas sobre as características das fraçôes das substâncias húmicas do solo. Revista Ceres, v.46, p.67-81, 1999.

SÁ, J.C.M.; CERRI, C.C.; DICK, W.A.; LAL, R.; VENZKE FILHO, S.P.; PICCOLO, M.C.; FEIGL, B.E. Organic matter dynamics and carbon sequestration rates for a tillage chronosequence in a Brazilian Oxisol. Soil Science Society American Journal, v.65, p.1486-1499, 2001.

SANTOS, G.A.; CAMARGO, F.A.O. (Ed.). Fundamentos da matéria orgânica do solo: ecossistemas tropicais e subtropicais. Porto Alegre: Genesis, 1999. 508p.

SARGENTINI JUNIOR., E.; ROCHA, J. C.; ROSA, A. H.; ZARA, L.F.; SANTOS, A. Substâncias húmicas aquáticas: fracionamento molecular e caracterizaçáo de rearranjos internos após complexação com íons metálicos. Química Nova, v.24, p.339-344, 2001.

SPARKS, D.L. Elucidating the fundamental chemistry of soils: Past and recent achievements and future frontiers. Geoderma, v.100, p.303-319, 2001. 
SILVA, J.E.; RESCK, D.V.S. Matéria orgânica do solo. In: VARGAS, M.A.T.; HUNGRIA, M. (Ed.). Biologia dos solos dos cerrados. Planaltina: EMBRAPA Cerrados, 1997. p.467-524.

SISTI, C.P.J.; SANTOS, H.P.; KOHHAN, R.; ALBES, B.J.R.; URQUIAGA, S.; BODEY, R.M.. Change in carbon and nitrogen stocks in soil under 13 years of conventional or zero tillage in southern Brazil. Soil and Tillage Research, v.76, p.39-58, 2004.

SOUZA, W.J.O.; MELO, W.J. Matéria orgânica de um Latossolo submetido a diferentes sistemas de produção de milho. Revista Brasileira de Ciência do Solo, v. 27, p. 1113-1122, 2003.

STEVENSON, F. J. Humus chemistry. New York: Wiley \& Sons; 1982. $198 \mathrm{p}$
STEVENSON, F.J. Humus chemistry: genesis, composition, reactions. New York: J. Wiley, 1994. 496p.

SWIFT, R.S. Organic matter characterization. In: SPARKS, D.L.; PAGE, A.L.; HELMKE, P.A.; LOEPPERT, R.H.; SOLTANPOUR, P.N.; TABATABAI, M.A.; JOHNSTON, C.T.; SUMNER, M.E. (Ed.). Methods of soil analysis. Madison: Soil Science Society of America: American Society of Agronomy, 1996. p.1011-1020. (Soil Science Society of America Book Series, 5)

TORRES, J.L.R; PEREIRA, M.G. Dinâmica do potássio nos resíduos vegetais de plantas de cobertura no cerrado. Revista Brasileira de Ciência do Solo, v.32, p. 1609-1618, 2008.

YOEMANS, J.C.; BREMNER, J.M. A rapid and precise method for routine determination of organic carbon in soil. Soil Science and Plant Analysis, v.19, p.1467-1476, 1988. 